Original Article

\title{
A study on knowledge of patients with end stage renal disease towards dialysis in a tertiary care hospital in Dhaka city
}

\author{
Tufayel Ahmed Chowdhury ${ }^{1}$, Sarwar Iqbal ${ }^{1}$, Umme Salma Talukder ${ }^{2}$, Mehruba Alam Ananna ${ }^{1}$, \\ A.S.M. Manzur Morshed Bhuiyan ${ }^{1}$, Mustarshid Billah ${ }^{1}$, Md. Abdur Rahim ${ }^{1}$, Tabassum Samad ${ }^{1}$, \\ Rana Mokarrom Hossain ${ }^{3}$ \\ ${ }^{1}$ Deptartment of Nephrology, BIRDEM General Hospital, Dhaka, Bangladesh \\ ${ }^{2}$ Department of Psychiatry, BIRDEM General Hospital, Dhaka, Bangladesh \\ ${ }^{3}$ Department of Nephrology, Bangabandhu Sheikh Mujib Medical University, Dhaka, Bangladesh
}

\begin{abstract}
Background and objective: There are approximately two million patients suffering from end stage renal disease (ESRD) worldwide requiring renal replacement therapy (RRT) in the form of dialysis. There are very few statistics regarding the knowledge and attitude towards dialysis among ESRD patients in Bangladesh. The present study was undertaken to understand the existing knowledge of the patients with ESRD regarding dialysis.

Methods: This cross sectional descriptive study was done on 104 patients with ESRD requiring immediate dialysis. This study was conducted in the department of Nephrology, BIRDEM General Hospital, Dhaka, Bangladesh over a period of six months. After obtaining informed consent the participants were given a self-administered questionnaire that included questions on socio-demographic status, age, gender, different aspects of knowledge about dialysis and the reasons to accept and refuse dialysis for the treatment of ESRD.
\end{abstract}

Results: A total of 104 patients with ESRD were enrolled in the study. The mean age was $54.20( \pm 11.82)$ years, $87.5 \%$ were more than 40 years of age, and $72.1 \%$ were male. Eighty two percent mentioned diabetes as the cause of kidney disease. About half of the respondents $(52.88 \%)$ knew dialysis as an option for the treatment of ESRD followed by kidney transplant $(11.54 \%)$. A few (7.3\%) mentioned medicine and dietary modification as the treatment. There was no statistical association between prior knowledge and agreeing to do dialysis $\left(\mathrm{X}^{2}=\right.$ $0.7814 ; \mathrm{p}=0.376699)$. Most of the patients $(78 \%)$ gathered knowledge about dialysis from doctors. Seventy two patients (69.2\%) agreed to do dialysis. Among them 37 patients $(51.4 \%)$ agreed as they considered it as a part of treatment and 32 patients $(44.4 \%)$ agreed because they were advised by doctors. Reasons for refusal to do dialysis were - fear of death (59.37\%), financial constraints $(31.25 \%)$ and lack of availability of dialysis centre $(9.37 \%)$ Among study populations, only 20 patients $(19.2 \%)$ mentioned about peritoneal dialysis (PD) and all of them $(100 \%)$ were informed by doctors.

Conclusion: The present study has demonstrated that prior knowledge on dialysis has no influence on the decision to do dialysis for the treatment of ESRD. Availability and access to dialysis facility and counseling on beneficial aspects of dialysis is required to motivate the patients for dialysis with ESRD. In addition to health care providers, social media may play an important role in promoting public awareness regarding dialysis as a treatment modality of ESRD.

IMC J Med Sci 2017; 11(1): 11-14

Address for Correspondence:

Dr. Tufayel Ahmed Chowdhury, Registrar, Department of Nephrology, BIRDEM General Hospital, 122, Kazi Nazrul

Islam Avenue, Shahbag, Dhaka.Email:dr_topu11@yahoo.com 


\section{Introduction}

There are approximately two million patients suffering from end stage renal disease (ESRD) worldwide. The reported prevalence of ESRD is between 800 to 2000 per million population in countries of European Union, USA and Japan [1] while it is100 per million population in developing country like India. Reported low prevalence of ESRD in developing countries is probably due to lack of access of chronic kidney patients to healthcare facilities and under reporting. The estimated prevalence of chronic kidney disease in Bangladesh is about 16-18\% and there would be about 30,000 new cases of ESRD per year [2]. Patients with ESRD require renal replacement therapy (RRT) either in the form of dialysis or kidney transplant. In Bangladesh, there are now approximately 84 dialysis centers in the whole country half of which are located in Dhaka city and remaining are in six large cities of the country [2].

Approximately, 800 patients are enrolled for hemodialysis in our BIRDEM hospital every year [3]. RRT in the form of dialysis improves the quality of life of patients with ESRD. But many with ESRD are not aware of the benefit of RRT or dialysis due to their lack of knowledge about it and suffer from debilitating morbidities. There are very few statistics regarding the knowledge about dialysis among ESRD patients. This study was therefore, undertaken to understand the existing knowledge of the ESRD patients regarding dialysis.

\section{Methodology}

This study was conducted at the department of Nephrology, BIRDEM General Hospital, Dhaka, from January 2016 to June 2016. Informed consent was obtained from each participant prior to enrollment in the study.

The present cross-sectional descriptive study was conducted on patients with ESRD requring immediate dialysis. ESRD was defined as chronic kidney disease (CKD), with irreversible deterioration in renal function, developing over a period of years and death is likely without renal replacement therapy [4]. Patients with acute kidney injury, acute stroke, unconscious and mentally confused were excluded. A predesigned questionnaire was used to collect data on age, gender, different aspects of knowledge about ESRD, renal replacement therapy specially dialysis. Appropriate statistical tests were used to analyze the data.

\section{Results}

Out of 104 patients $87.5 \%$ were more than 40 years of age and $72.1 \%$ were male. Of the 104 participants, $51.9 \%$ had monthly income of more than Tk. 20,000. Table-1shows the detail age, gender and average monthly family income of the study population. Majority patients $(81.7 \%)$ stated diabetes as the cause of kidney disease while $9.6 \%$

Table-1: Demographic characteristics of the study population $(n=104)$

\begin{tabular}{lc}
\hline Demographic characteristics & Number (\%) \\
\hline Gender & $75(72.1)$ \\
Male & $29(27.9)$ \\
Female & \\
Age (years) & $13(12.5)$ \\
$30-40$ & $91(87.5)$ \\
$>40$ & $11-80$ \\
Range & \\
Monthly income (Tk) & $18(17.3)$ \\
$<10,000$ & $32(30.8)$ \\
$10,000-20,000$ & $54(51.9)$ \\
$>20,000$ & \\
\hline
\end{tabular}

Table-2: Knowledge of the study population about the cause and treatment options of ESRD $(n=104)$

\begin{tabular}{lc}
\hline \multicolumn{1}{c}{ Parameter } & Number (\%) \\
\hline A. Cause of kidney disease & \\
Diabetes & $85(81.7)$ \\
High blood pressure & $10(9.6)$ \\
Pain killer medicine & $5(4.8)$ \\
Infection & $4(3.8)$ \\
B. Treatment options of & \\
kidney disease & \\
Hemodialysis & $35(33.7)$ \\
Peritoneal dialysis & $20(19.2)$ \\
Do not know & $21(20.2)$ \\
Kidney transplant & $12(11.5)$ \\
Medicine & $8(7.7)$ \\
Medicine+dietary modification & $8(7.7)$ \\
\hline
\end{tabular}


mentioned high blood pressure and only a few $(4.8 \%$ and $3.8 \%)$ mentioned pain killer medicine and infection as the cause (Table2). Of the total respondents, $55(52.9 \%)$ knew dialysis as the treatment of ESRD of which $35(33.7 \%)$ and 20 (19.2\%) mentioned hemodialysis and PD respectively. Only $11.5 \%$ mentioned kidney transplant as an option. Most of the patients (78.2\%) gathered knowledge about dialysis from doctors while only $20.8 \%$ and $1.8 \%$ knew it from other patients and media respectively (Table 3 ).

Table-3: Sources of the knowledge about dialysis $(n=55)$

\begin{tabular}{lc}
\hline $\begin{array}{c}\text { Sources of knowledge about } \\
\text { dialysis }\end{array}$ & Number (\%) \\
\hline Doctor & $43(78.2)$ \\
Other kidney patients & $11(20.0)$ \\
Media & $1(1.8)$ \\
\hline
\end{tabular}

Table 4 shows that out of 104 respondents, 72 $(69.2 \%)$ agreed to do dialysis for the treatment and of which $55(52.9 \%)$ had knowledge about dialysis and $49(47.1 \%)$ had no prior knowledge regarding dialysis as a modality of treatment. However, $73.5 \%$ of those who did not know dialysis as a mode of treatment of ESRD agreed to do dialysis compared to $65.5 \%$ of those who knew dialysis as a treatment. But, there was no statistical association between prior knowledge and agreeing to do dialysis $\left(X^{2}=0.7814 ; p=0.376699\right)$. Reasons for agreeing and refusing dialysis as a treatment modality of severe kidney disease by the study

Table-4: Respondents' knowledge and decision to do dialysis

\begin{tabular}{lccc}
\hline Respondent & $\begin{array}{c}\text { Total } \\
\text { Number } \\
(\boldsymbol{\%})\end{array}$ & $\begin{array}{c}\text { Agreed } \\
\text { to do } \\
\text { dialysis } \\
\text { Number } \\
(\%)\end{array}$ & $\begin{array}{c}\text { Refused } \\
\text { to do } \\
\text { dialysis } \\
\text { Number } \\
(\%)\end{array}$ \\
\hline $\begin{array}{l}\text { Had previous } \\
\text { knowledge about }\end{array}$ & 55 & 36 & 19 \\
dialysis & $(52.9)$ & $(65.5)$ & $(34.5 \%)$ \\
$\begin{array}{l}\text { Had no knowledge } \\
\text { about dialysis }\end{array}$ & 49 & 36 & 13 \\
Total & $(47.1)$ & $(73.5)$ & $(26.5 \%)$ \\
& 104 & 72 & 32 \\
& & $(69.2)$ & $(30.8)$ \\
\hline
\end{tabular}

Note: $X^{2}=0.7814 ; p=0.376699$ population are shown in Table-5. Out of 72 respondents who agreed to do dialysis for ESRD, $37(51.4 \%)$ agreed because they considered dialysis as part of the treatment for kidney disease while $32(44.4 \%)$ agreed because it was advised by the doctor. The reason for refusal to do dialysis was fear of death by $59.3 \%$ and financial constraint as $31.3 \%$ (Table-5).

Table-5: Reasons for agreeing and refusing dialysis $(n=104)$

\begin{tabular}{lc}
\hline \multicolumn{1}{c}{ Reasons for } & Number (\%) \\
\hline A. Agreeing to do dialysis $(\mathbf{n}=\mathbf{7 2})$ & \\
Dialysis is a part of treatment & $37(51.4)$ \\
Advised by doctors & $32(44.4)$ \\
As per wish of the family & $3(4.2)$ \\
B. Refusal to do dialysis $(\mathbf{n}=\mathbf{3 2})$ & \\
Fear of death & $19(59.3)$ \\
Financial constraint & $10(31.3)$ \\
Lack of dialysis facility & $3(9.4)$ \\
\hline
\end{tabular}

\section{Discussion}

The present study has demonstrated that majority of the respondents with ESRD were male and above 40 years of age. The male predisposition in our series could be due to importance of male population in the society and their access to health care services. Over $80 \%$ of the study population knew diabetes as a cause of ESRD while few mentioned hypertension and medicine as the possible causes. Most of the study partcipants were registered diabetic patients at BIRDEM hospital. BIRDEM hospital is a national referral center for diabetes and patients are regularly educated about the complications of diabetes namely kidney disease Therefore, this could be the reason for mentioning diabetes as a possible cause of kidney disease by the respondents and therefore might not reflect the knowledge of the general kidney patients in the country. Over half of the respondents $(53.0 \%)$ stated dialysis as the treatment for ESRD and $11.54 \%$ thought of kidney transplant. More than $75 \%$ of the respondents obtained information about dialysis from the doctors. It is important to note that only about $1.8 \%$ came to know about dialysis from media, Therefore, media and social networks need to provide more efforts in building awareness about such a life threatening disease. 
It was interesting to note that prior knowledge about dialysis as a modality of treatment of ESRD did not have any significant influence on the decision to do dialysis or not (Table 4). Doctors' advice was the main reason to decide in favor of doing dialysis. On the other hand, fear of death $(59.3 \%)$ and financial constrains $(31.3 \%)$ were the main reason to refuse dialysis. Therefore, proper counseling regarding its beneficial aspect like improved quality of life and availability of facility at low cost would help people to accept dialysis for the treatment of ESRD. It has been reported earlier that in $60 \%$ case, fear of death was the reason for non-compliance to do dialysis in ESRD [5].

Only about $19 \%$ of our respondents heard about PD. Patients with chronic kidney disease should be made aware and motivated for PD as it is less expensive and does not require costly machines and accessories [6-8]. Also, it is usually not associated with infection like hepatitis $B$ and $C$ as well as the quality of life of patients on PD is as good as that of HD [6-8]. The study findings indicate that there is a need for counseling of chronic kidney patients to create awareness about the role and values of dialysis as a treatment option of ESRD. Peritoneal dialysis should further be encouraged to make it familiar and popular amongst the kidney patients.

\section{Author contributions}

The first two authors had equal contributions to this work.

\section{References}

1. Barsoum RS. Chronic Kidney Disease in the Developing World. N Engl J Med. 2006; 354 (10): 997-999.
2. Rashid HU. Management of end stage renal disease-Bangladesh perspective. The Open Urology \& Nephrology J. 2014; 7: 108-112.

3. Diabetic Association of Bangladesh. Statistical year book 2012-2013. Dhaka: Bangladesh Diabetic Association of Bangladesh; 2013. p482.

4. Gouddard J, Turn AN. Kidney and urinary tract disease. In: Walker BR, College NR, Ralston SH, Penman ID, editors. Davidson's principles and practice of medicine. 22nd eds. Edinburgh: Churchill Livingstone Elsivier; 2014; p461523.

5. Iqbal S, Talukder US, Chowdhury TA, Billah M, Ananna MA, Rahim MA et al. Psychiatric comorbidities in ESRD patients recently placed on haemodialysis: a prospective observational study from a tertiary care hospital. Bangladesh Crit Care J. 2016; 4(1): 23-27.

6. Nayak KS, Prabhu MV, Siroj KA, Subhramanyan SV, Sridhar G. Peritoneal dialysis in developing countries. Contriub Nephrol 2009; 163: 270277.

7. Li PK, Lui SL, Leung CB, Yu AW, Lee E, Just PM et al. Increased utilization of peritoneal dialysis to cope with mounting demand for renal replacement therapy-perspective from Asian countries. Perit Dial Int 2007; 27(2): S59-61.

8. Just PM, Riella MC, Tschosik EA, Noe LL, Bhattacharyya SK, de Charro F. Economic evaluation of dialysis treatment modalities. Health Policy 2008; 86: 163-80. 